\title{
A REFORMA TRABALHISTA E OS REFLEXOS DO FIM DA CONTRIBUIÇÃO SINDICAL COMPULSÓRIA NOS SINDICATOS
}

\section{THE LABOR REFORM AND THE REFLECTIONS OF THE END OF COMPULSORY TRADE UNION CONTRIBUTION IN TRADE UNIONS}

\section{DEBORA CRISTINA DE CASTRO DA ROCHA}

Mestranda em Direito Empresarial e Cidadania pelo UNICURITIBA e pós-graduanda em Direito Imobiliário pela Escola Paulista de Direito. Especialista em Direito e Processo do Trabalho e em Direito Constitucional pela Academia Brasileira de Direito Constitucional. Professora de Direito e Processo do Trabalho, pesquisadora do CNPQ pelo Centro Universitário Curitiba nos grupos de pesquisa "Reforma Trabalhista" e "Responsabilidade e Função Social da Empresa", Presidente da Comissão de Direito Imobiliário OAB/SJP, Vice-Presidente da Comissão de Fiscalização, Ética e Prerrogativas OAB/SJP e integrante da Comissão de Direito Imobiliário OAB/PR. Advogada.

\section{EDILSON SANTOS DA ROCHA}

Pós-graduando em Direito Imobiliário pela Escola Paulista de Direito e pesquisador CNPQ pelo Centro Universitário Curitiba nos grupos de pesquisa "Reforma Trabalhista", "Compliance" e "Responsabilidade e Função Social da Empresa". Graduado em Tecnologia em Fabricação Mecânica pelo Ensitec, acadêmico de Direito pela Faculdade da Indústria

\section{RESUMO}

Pretende-se com esta pesquisa, uma discussão acerca do impacto da Lei $13.467 / 2017$ ao sindicalismo, no que tange a proibição do desconto ou cobrança 


\title{
Personalidade Acadêmica Homenageada:
}

Carlos Aurélio Mota de Souza (Universidade Ibirapuera - UNIB)

sem a prévia e expressa anuência do trabalhador e a voluntariedade da sua ocorrência. Assim, a partir de uma contextualização histórica, busca-se na essência da criação da contribuição sindical, uma maior compreensão dos efeitos da reforma acerca do tema, tendo em vista esta ter tornado facultativa a contribuição, e se especificamente, aos trabalhadores, tal facultatividade poderá contribuir para a liberdade sindical no Brasil, e por outro lado, se esteja diante de um problema de financiamento dos sindicatos profissionais, e por consequência, da própria defesa dos respectivos trabalhadores. Buscar-se-á ainda, discorrer acerca da não recepção da Convenção n. 87 de 1948 pela Constituição de 1988, que dispõe acerca da liberdade sindical. E se a alteração promovida pela Reforma Trabalhista poderá proporcionar maior aproximação dos sindicatos com os trabalhadores, influenciando a anuência com o desconto da contribuição sindical.

PALAVRAS-CHAVE: Lei 13.467/2017; Sindicalismo; Contribuição Sindical; Reforma Trabalhista; Liberdade Sindical.

\begin{abstract}
This discussion seeks to discuss the impact of Law 13467/2017 on trade unionism, regarding the prohibition of deduction or collection without the prior and express consent of the worker and the voluntariness of its occurrence. Thus, from a historical context, the essence of the creation of the union contribution is sought, a greater understanding of the effects of the reform on the subject, in order to make the contribution optional, and if specifically to the workers, this faculty can contribute to freedom of association in Brazil, and, on the other hand, there is a problem of financing trade unions and, consequently, the defense of the workers themselves. It will also be sought to find out whether the union uniqueness imposed by the 1988 Constitution could harm Convention No. 87 of 1948 which deals with freedom of association. And if the amendment promoted by the Labor Reform can bring the unions closer to the workers, influencing the agreement with the discount of the union contribution.
\end{abstract}


KEYWORDS: Law 13467/2017; Trade Unionism; Union Contribution; Labor Reform; Freedom Of Association.

\section{INTRODUÇÃO}

A intitulada reforma trabalhista, por meio da Lei 13.467, de 13/07/2017 modificou o artigo 579 da Consolidação das Leis do Trabalho, convertendo a dedução da contribuição sindical vinculada, à anuência prévia e explícita daqueles que façam parte de certa categoria econômica ou profissional, em favor do sindicato representante da mesma classe.

Por conseguinte, verificou-se uma profunda alteração na arrecadação sindical, pois somente será possível a cobrança dos montantes devidos pela totalidade da categoria mediante a hipótese de efetiva concordância de seus integrantes.

Erigido e sustentado por trabalhadores, o histórico sindical brasileiro, surgiu no final do século XIX, em consonância com a evolução de nossa economia, no tempo em que o epicentro agrícola era o café, por conseguinte, no transcorrer dos anos, e em decorrência do constitucionalismo brasileiro se originara a ascensão da concepção do sindicalismo como o direito de associação para manutenção e proteção dos direitos dos operários.

A partir da existência de apenas um sindicato por categoria em cada localidade, - sistema este, adotado pelo legislador brasileiro -, ou seja, a partir da unicidade sindical é que fora instituída a contribuição sindical.

A unicidade é caracterizada pela imposição legal, logo, há uma distinção entre a pluralidade sindical e a unicidade sindical, que é a subsistência de um só sindicato por categoria, que ocorre por deliberação dos envolvidos.

Por conseguinte, não só os grandes sindicatos e efetivos podem perdurarse, mas também todos os demais, pois têm direito à percepção da contribuição, que 


\section{Personalidade Acadêmica Homenageada:}

Carlos Aurélio Mota de Souza (Universidade Ibirapuera - UNIB)

no caso dos empregados, diz respeito ao salário de um dia de trabalho por ano, a despeito de sua ação efetiva em benefício da categoria.

Observa-se, portanto, que se trata de uma transformação muito sensível, transformando a contribuição sindical antes compulsória, em facultativa, agora sob a total dependência da expressa anuência do trabalhador.

Não restam dúvidas acerca do caráter polêmico da compulsoriedade da contribuição sindical, a qual desagrada a maioria dos contribuintes, a classe empresária, e ainda, grande parcela dos sindicatos profissionais, principalmente, os sindicatos de maior representatividade.

O artigo 8ํ, IV da Constituição Federal no que diz respeito à arrecadação sindical instituída pela assembleia geral do sindicato, anota o caráter legal da contribuição sindical disposta em lei. E no texto anterior à Lei 13.467, de 13/07/2017, a Consolidação das Leis do Trabalho em seu artigo 579 dispunha que a contribuição era obrigatória a todos os integrantes de certa categoria econômica ou profissional, ou ainda profissão liberal, em favor do respectivo sindicato.

Sob o a perspectiva do Direito Internacional do Trabalho, a contribuição obrigatória fundada na unicidade sindical, colide com a Convenção 87 da Organização Internacional do Trabalho, que estabelece a liberdade e a autonomia sindical, o que só é possível a partir da liberdade de afiliação e representatividade da instituição não somente no que diz respeito aos seus filiados, mas em relação a toda organização civil.

Um ponto a se evidenciar a respeito do assunto é que o sistema administrativo e a atividade dos diversos sindicatos profissionais e patronais são bastante complexos, e seus encargos financeiros são correspondentes a sua arrecadação, situação já de muito tempo. Destarte, é provável que a remoção da contribuição sindical imperativa, subitamente, tanto num grande sindicato, quanto numa instituição de menor porte e representatividade, cause graves abalos financeiros.

\section{HISTÓRICO DOS SINDICATOS E A CRIAÇÃO DAS CONTRIBUIÇÕES SINDICAIS}




\section{Personalidade Acadêmica Homenageada:}

\section{Carlos Aurélio Mota de Souza (Universidade Ibirapuera - UNIB)}

\subsection{A CRIAÇÃO DOS SINDICATOS}

O histórico constitucional brasileiro nos leva ao sistema sindical hodiernamente vigente, o qual provém do início do século XX. Todavia, a doutrina tem acautelado que o sindicalismo brasileiro ainda está em busca de uma sistemática legislativa que o embase em fundamentos democráticos após seguir por um longo trajeto em seu histórico politico e trabalhista (NASCIMENTO, 2015, p. 99).

O exemplo do que ocorrera em muitos outros países, do mesmo modo no Brasil, as corporações de ofício antecederam o direito de associação e os sindicatos, em que num, primeiramente, era considerado ilícito, para posteriormente ser restabelecido, tendo sido vigorosamente inspirado pelo movimento corporativista do Estado Novo, durante a década de 30 do século $X X$ e, por fim, reestruturado no findar da ditadura militar, na década de 80 do século XX (NASCIMENTO, 2015, p. 99).

As ligas operárias, sociedades e uniões, cujas bandeiras, ainda difusivas, ansiavam melhores condições de trabalho, dentre os quais salários mais dignos, jornadas de trabalho reduzidas e a assistência social, foram as associações precursoras de trabalhadores brasileiros consignadas pela doutrina (NASCIMENTO, 2015, p. 99).

A partir de um falso compromisso de condições de trabalho melhores, os estrangeiros posteriormente ao fim da escravidão, em 1888, foram conduzidos ao Brasil e ao adentrar, visualizaram uma situação de semiescravidão, as quais foram de forte influência para que no Brasil fossem formados os sindicatos. Revoltosos e trazendo consigo princípios anarquistas e socialistas, iniciaram as lutas pela constituição de sindicatos sem viés político, com intuito da melhoria das condições de trabalho e que batalhasse por direitos do trabalhador, tal e qual o direito à greve.

A base ideológica, todavia, não ter criado uma representatividade sindical, acabou sendo consolidada dentre a classe trabalhadora dando cabo à uma série de greves no Brasil em meados de 1900 e 1920.

Os sindicatos urbanos foram regulamentados em 1907, mediante o decreto no 1637, e para se formarem, tiveram que abranger classes semelhantes ou 


\section{Personalidade Acadêmica Homenageada:}

Carlos Aurélio Mota de Souza (Universidade Ibirapuera - UNIB)

minimamente conexas entre si, pois as funções prioritárias destes sindicatos era a tutela geral dos anseios dos trabalhadores individual e coletivamente.

As entidades que sobrevieram de sindicato, tão somente detinham o rótulo. Dentre os agricultores, sequer uma base intelectual existia que lhes garantisse a possibilidade de organização, ademais, estavam financeiramente dependentes dos seus senhores, os quais não hesitavam em demitir aqueles que ousassem exigir qualquer melhoria, já que direitos não estavam conceituados na legislação (VIANAS et al, 1981, p. 958).

Getúlio Vargas se deparou com um Brasil de grandes agitações políticas ao incumbir-se do poder, após um golpe de estado, diante de uma economia que se encontrava fundamentada na exportação de café já decrescente e em um enorme descontentamento dos trabalhadores, que indispostos por não alcançarem medidas efetivas de mudança, promoviam greves, inspirados, principalmente, pelos estrangeiros, que consigo trouxeram a ideologia anarco-sindicalista.

Ao implementar um governo intervencionista, uma das primeiras deliberações de Getúlio Vargas, foi a permissão para que fosse limitado a um terço os trabalhadores estrangeiros participantes dos sindicatos, pois entendia que estes tinham nas manifestações trabalhistas, razão para demonstrar suas convicções políticas, buscando assim manter sob controle as greves recorrentes que acometiam as produções brasileiras e garantir determinada estabilidade politica.

Em 1930 foi criado o Ministério do Trabalho, que tem como uma de suas razões de ser, a estruturação na força de trabalho em cooperação com o Estado. Estado esse que tem como objetivo manter sob seu controle a criação de sindicatos, que tornaram-se colaboradores do Poder Público, delimitando categorias, bem como possibilitando o controle sob as ações dos sindicatos.

Em 1931 entrou em vigor o Decreto № 19.770, em que se afirmara que os sindicatos ou associações de classe seriam os para-choques dessas tendências conflituosas, e que os salários mínimos, os regimes e as horas de trabalho seriam assuntos prioritários, sob os olhos do cauteloso Estado. A resolução dos conflitos de trabalho seriam do mesmo modo, de sua responsabilidade, com o amparo de pessoas alheias ao antagonismo de classe e com recurso a tribunal superior. 


\section{Personalidade Acadêmica Homenageada:}

Carlos Aurélio Mota de Souza (Universidade Ibirapuera - UNIB)

Ademais, uma classe ou profissão encontraria no sindicato respectivo, o porta-voz autorizado e competente (AROUCA, 2003).

Às associações permitiu-se pleitear melhorias em suas condições de trabalho em face do ministério, aumentos salariais e fiscalização, todavia, sempre sob o cunho probatório do Estado, ademais também podiam pactuar contratos de trabalho ou convenções com os demais sindicatos, ou ainda, com a classe patronal.

O Estado passou a exigir pareceres dos sindicatos que delimitassem suas atividades, sendo, portanto, os estatutos dos sindicatos, submetidos a um processo de padronização. Permitiu-se a criação de apenas um sindicato por território, pondo fim a pluralidade sindical. Garantiu-se ao diretor sindical sua estabilidade no emprego, tendo sido adotado o sistema utilizado até os dias de hoje, de confederação, federação e sindicatos.

Os preceitos da autonomia sindical e a pluralidade sindical foram amparados pela Constituição de 1934, entretanto, delimita o montante de trabalhadores em reuniões dos sindicatos e mantém um delegado do ministério controlando as reuniões dos sindicatos. Sendo ainda proibida qualquer afiliação a organizações estrangeiras, salvo se autorizada expressamente pelo Ministério do Trabalho.

Havia obrigatoriedade de consentimento do Ministério do Trabalho mediante seu estatuto social, para estabelecimento dos sindicatos, na hipótese da impossibilidade da sindicalização por ofícios equivalentes, sendo assentida por oficio a cooperação em sindicatos. Os cargos diretivos dos sindicatos não eram passíveis de remuneração, cabendo a suspensão em caso de inobservância de quaisquer das regras dispostas, possivelmente até mesmo ser o dirigente retirado ou o sindicato suspenso, multado, ou até mesmo, ocorrer sua extinção.

Em busca do aumento do controle sobre os sindicatos, o governo revoga o pluralismo sindical mediante a nova Constituição de 1937 que pondo fim ao que fora instituído em 1934, regressa às diretrizes definidas no decreto ํㅜ⒚770/31.

Nesse sistema confederações, federações e sindicatos, eram como degraus de uma escada que desencadearia na instituição. Diante dessa medida, buscou o governo ter em suas mãos, a economia brasileira, para melhor prosseguir com os seus programas de política trabalhista e econômica. Para tanto, entendeu 


\section{Personalidade Acadêmica Homenageada:}

Carlos Aurélio Mota de Souza (Universidade Ibirapuera - UNIB)

indispensável evitar o antagonismo de classes; daí, a integração das forças produtivas, dos empresários, dos trabalhadores, e dos profissionais liberais, monoliticamente e não em grupos divididos e com possibilidades basilares conflitivas (NASCIMENTO, 2005, p. 92).

Com o declínio de Getúlio Vargas em 1946, o qual criou em seu governo a Consolidação das Leis Trabalhistas, a partir da carta que dispõe as relações de trabalho, ocorreu como progresso para os sindicatos a outorga do decreto lei $n^{-}$ 9.070/1946, sendo um permissivo ao direito de greve, muito utilizado como forma de pressão nas negociações coletivas, contudo, não alterando a estrutura sindical, ou mesmo, reduzindo a intervenção estatal nos sindicatos.

Poucas foram as mudanças durante o regime militar, todavia, há de destacar-se o aumento das funções sindicais em nosso sistema político, realizando greves e passeatas em movimentos em favor da melhoria das condições de trabalho, surgindo com robustez nessa época as centrais sindicais que passam a liderar os movimentos.

\subsection{A CRIAÇÃO DA CONTRIBUIÇÃO SINDICAL}

De natureza tributária e no intuito de gerar um valor pago compulsoriamente pelos trabalhadores, a contribuição sindical fora criada pelo governo de Getúlio Vargas no ano de 1939, assim sendo, portanto, a base financeira do Sistema Sindical, fortalecendo-o com recursos para que pudesse se manter de forma autônoma, independentemente de intervenção estatal e tendo assim maior representatividade frente às suas classes.

Muito embora os sindicatos consistam em entidades sem fins lucrativos, arrecadam um grande montante financeiro de forma a viabilizar a representação de seus sindicalizados. Diante disso, fora determinado o envio para as entidades sindicais, representantes do trabalhador por via direta, uma contribuição concernente a um dia anual de trabalho.

Veja-se que três são os pilares fundamentais que sustentam o regime sindical estabelecido pela Constituição de Federal de 1988, em que se tem: a 


\section{Personalidade Acadêmica Homenageada:}

Carlos Aurélio Mota de Souza (Universidade Ibirapuera - UNIB)

unicidade sindical disposta em seu art. 8으. II, a representatividade compulsória disposta no art. $8^{\circ}$, III, e a contribuição sindical no art. 8ํㅡ, IV, parte final.

Denota-se, assim, que a Constituição Federal de 1988 é incoerente quanto à contribuição obrigatória, tendo em vista que, em seu artigo $8^{\circ}$ expressa a liberdade de associação do trabalhador ao sindicato, ainda que este seja impossibilitado de escolher sindicato distinto, em se considerando o modelo de unicidade sindical adotado no Brasil.

Em se considerando o exposto, em tese seria indevida a obrigatoriedade da contribuição para os não sindicalizados, todavia em seu inciso IV, a Carta Magna dispõe que compete a assembleia geral tratar a respeito da contribuição sindical, portanto, a mesma continuava sendo cobrada daqueles que não eram sindicalizados, compulsoriamente, exceto dos profissionais liberais, que por não manterem vínculo de emprego, encontravam-se fora da abrangência do âmbito da justiça do trabalho, descabendo assim, serem representadas pelos sindicatos.

Demonstra-se, portanto, desarrazoada a interpretação que torna compulsória a integralidade dos trabalhadores da categoria, uma contribuição estipulada por uma entidade sindical, quando todo o sistema assegura a liberdade e filiação, sendo garantida a livre associação profissional ou sindical (SUSSEKIND, 2000, p. 1149).

O Tribunal Superior do Trabalho deu publicidade ao Precedente Normativo $119^{1}$, no qual expõe seu entendimento acerca da contribuição sindical, no sentido de que não sendo a mesma compulsória aos não filiados ao sindicato, e mesmo assim, se mantida a compulsoriedade, tem-se ofendido o direito à liberdade plena de sindicalização e associação, convenção coletiva, sentença normativa ou mesmo cláusula constante de acordo.

\footnotetext{
${ }^{1}$ № 119 CONTRIBUIÇÕES SINDICAIS - INOBSERVÂNCIA DE PRECEITOS CONSTITUCIONAIS (mantido) - DEJT divulgado em 25.08.2014 "A Constituição da República, em seus arts. 5ำ, XX e 8ㅜ, $\mathrm{V}$, assegura o direito de livre associação e sindicalização. É ofensiva a essa modalidade de liberdade cláusula constante de acordo, convenção coletiva ou sentença normativa estabelecendo contribuição em favor de entidade sindical a título de taxa para custeio do sistema confederativo, assistencial, revigoramento ou fortalecimento sindical e outras da mesma espécie, obrigando trabalhadores não sindicalizados. Sendo nulas as estipulações que inobservem tal restrição, tornam-se passíveis de devolução os valores irregularmente descontados."
} 


\section{Personalidade Acadêmica Homenageada:}

Carlos Aurélio Mota de Souza (Universidade Ibirapuera - UNIB)

O Supremo Tribunal Federal se fundamentando no art. $8^{\circ}$, IV da Constituição Federal, entendeu que, por ser o encargo despido de natureza tributária, deve sujeitar somente os filiados da entidade de representação profissional. Interpretação esta em plena conformidade com o principio da liberdade sindical consagrado em nossa Carta Magna, conforme decisão proferida no Recurso Extraordinário no 173.869, de relatoria do Ministro IImar Galvão e julgado em 22/04/1997.

Evidente, portanto, que a doutrina e a jurisprudência antes mesmo da Lei 13.467/2017 já era desfavorável à compulsoriedade da contribuição sindical, vindo esta tão somente a positivar sua facultatividade.

\section{CONTRIBUIÇÃO SINDICAL NA PERSPECTIVA DA LIBERDADE SINDICAL}

\subsection{A CONVENÇÃO 87 DA OIT - E A NÃO RECEPÇÃO PELA CONSTITUIÇÃO FEDERAL}

A convenção de n. 97 da OIT conjectura o pluralismo sindical, em outras palavras, a viabilidade de coexistência de mais de um sindicato em um mesmo contexto de representatividade, assim a classe trabalhadora e empregadora, sem qualquer distinção, tem o direito de filiar-se a entidades da sua preferência e de constituí-las, para fomentar e resguardar os interesses inerentes.

Em consonância com que aduz o art. 3.ำ da convenção OIT n.. 87 , é de direito às entidades sindicais, a elaboração de seus estatutos e regulamentos, eleger livremente os seus representantes e estruturar a própria administração, de organizar a gestão de suas atividades e de elaborar seu programa de ação (VIANNA, 2005).

Desde a sua elaboração, o sindicato tem que resguardar a sua liberdade para trabalhar sem ingerência do Estado. Pertence aos seus integrantes fundadores e, por conseguinte, aos sindicatos em si, tomar decisões livremente de como devem ser instituídos seus estatutos, inclusive, sobre quais fundamentos. Os sindicatos devem ter liberdade total sobre essa matéria, o que implica, inequivocamente, que 


\section{Personalidade Acadêmica Homenageada:}

Carlos Aurélio Mota de Souza (Universidade Ibirapuera - UNIB)

as autoridades públicas não devem impor uma determinada estrutura a essas entidades sindicais (GERNIGON, 2004, p. 229).

À vista disso, a convenção predispõe o pluralismo sindical, de outro modo, a unidade sindical que se alicerça no estabelecimento de várias instituições sindicais em uma mesma base territorial. Nesse ponto de vista, cabe salientar, ainda, que a convenção antevê do mesmo modo o direito de o sindicato se filiar as entidades estrangeiras e às organizações não governamentais, todavia não houve a ratificação Brasileira acerca da convenção n. 87 da OIT.

A liberdade sindical reconstitui a estabilidade entre os partícipes da negociação coletiva, a partir do permissivo dado aos trabalhadores de uma forma a exteriorizar os seus anseios, resguardar as suas propensões, e corrobora também, o poder de negociação coletiva. Desta forma, a liberdade sindical converte-se em uma espécie de fator de saneamento das relações trabalhistas, cooperando, consequentemente, para a paz e justiça social (GERNIGON, 2004, p. 229).

Impossível se vislumbrar a liberdade sindical sem o total apreço às liberdades civis, em se considerando que a liberdade sindical é uma ideia umbilicalmente ligada aos direitos humanos e ao espírito democrático (GERNIGON, 2004, p. 229).

No entanto, o entendimento foi de que a Constituição Federal de 1988 vedava a possibilidade da ratificação da Convenção 87 da OIT, eis que o permissivo dado pela Carta Magna era de apenas um sindicato em cada base territorial, e que esta não poderia ser inferior à área de um município.

A contribuição sindical a partir de imposição legal também não se harmonizava com a Convenção, tendo em vista que vai em desencontro da liberdade sindical, ou seja, de as pessoas livremente se filiarem à entidade sindical e colaborarem financeiramente de forma espontânea com as contribuições devidas, não de maneira obrigatória, mesmo porque, tal contribuição não diferencia o status de associado (MARTINS, 2010, p. 720).

A partir desses critérios, visualiza-se pelo que já fora explanado, que a liberdade sindical ainda está sob uma liberdade policiada, isto é, que existem 


\section{Personalidade Acadêmica Homenageada:}

Carlos Aurélio Mota de Souza (Universidade Ibirapuera - UNIB)

restrições, tanto para o estabelecimento de outros sindicatos, como a livre iniciativa de seu associado se filiar.

Resta evidente, portanto, que a dita liberdade sindical em verdade surgiu com sua liberdade controlada, de outro modo, um sistema misto entre a liberdade ilimitada e os limites prescritos pelo padrão corporativo (LOBATO, 2006, p. 175).

\subsection{O MODELO SINDICAL NA CONSTITUIÇÃO FEDERAL}

A Magna Carta em seu inciso IV, do artigo $8^{\circ}$, dispõe uma estruturação do sistema de representatividade sindical, que atua com um sistema hierarquicamente ordenado a partir de um estrutura piramidal, em que no topo estão as confederações, no nível intermediário as federações e no nível abaixo os sindicatos, onde há os sindicatos, representados pelas federações, a quem recorrem para a solução dos desacordos e acima desta, estão as confederações que buscam a solução dos problemas quando não é identificada a resolução pela federação.

À vista disso, como entidades sindicais de nível superior, tem-se as confederações e federações assim descritas pela CLT, em seu artigo 533. Para o estabelecimento de uma federação, necessária se faz a coexistência de ao menos cinco sindicatos em sua base de atividade, as federações, são em maior parte, entes estaduais. Para que ocorra a consolidação de uma confederação, faz-se imprescindível para que possam ter alcance nacional, que ao menos tenham três federações em sua base.

Tais conglomerados não podem ocorrer livremente, devendo ser obrigatoriamente da mesma categoria, em uma estrutura uniforme, em que se proporciona aos sindicatos, sempre em número maior do que cinco, - contanto que representem um conjunto de atividades ou profissões idênticas de forma absoluta, similares ou conexas -, ordenar-se em federação. A confederação é fundada por, no mínimo, três federações a ser sediada na capital federal (NETO, 2004, p. 1539).

A unicidade sindical provoca a subsistência de uma única associação representativa da mesma categoria em certo território. Somente um sindicato representa a categoria em determinado território, presumivelmente permitindo, se as 


\section{Personalidade Acadêmica Homenageada:}

Carlos Aurélio Mota de Souza (Universidade Ibirapuera - UNIB)

desagregações, as dissidências com os desmembramentos e as dissidências das categorias, que são estabelecidos no ato de instituição da corporação sindical (BATALHA, 1992, p. 115).

Para que seja estruturado um sindicato, se faz imprescindível uma base territorial mínima, assim sendo, não há permissivo de representação em uma área menor que a de um município. Destarte, qualquer sindicato que for formalizado, somente será viável se sua base for maior que um município, descabendo, dessa forma, os sindicatos distritais, por bairros ou ainda por entidades empresariais. Sendo esse princípio uma forma de mitigação à possibilidade de criação de muitos sindicatos, o que em tese representaria certa desagregação da categoria.

\section{IMPACTOS DA REFORMA NO FINANCIAMENTO SINDICAL}

\subsection{FINANCIAMENTO DA ATIVIDADE SINDICAL}

A base financeira das entidades sindicais deve ser debatida a partir das premissas dispostas na Constituição Federal de 1988, eis que enquanto o sistema sindical estiver sujeitado à unicidade sindical, que declara representativo exclusivamente um único sindicato por classe em determinada base territorial, e, em contrapartida, durante a negociação coletiva difundir seus efeitos para além dos trabalhadores afiliados, é indispensável estabelecer-se um tributo para seu financiamento, sob pena de se impossibilitar o andamento desse sistema.

Tem-se, por conseguinte, que a exigência de que os sindicatos de trabalhadores apresentem um comportamento ativo (negociado sobre o legislado) 


\section{Personalidade Acadêmica Homenageada:}

Carlos Aurélio Mota de Souza (Universidade Ibirapuera - UNIB)

sem que ao menos existam condições materiais para tal performance, é debilitar o movimento sindical e fomentar a insegurança jurídica (GUNTHER, 2017. p. 214).

Os recursos das organizações sindicais consistem no conjunto de bens que servem para o cumprimento dos propósitos sindicais de representação e de intervenção em prol dos interesses dos trabalhadores. No Brasil, o patrimônio das instituições sindicais se perfaz das receitas ordinárias e extraordinárias, que remonta às contribuições obrigatórias ou convencionadas que podem ser exigidas, assim como das doações, legados, sanções, bens e rendas advindos dos mesmos, dentre outros, em conformidade com o art. 548 da CLT (PEGO, 2012, p. 93).

No entanto, a contribuição sindical representa, em verdade, uma deformidade legal da representatividade do sindicato. Fundada em uma representação legal dos anseios gerais da classe conforme disposição do art. 138 da Carta de 1937, estipulou-se, legalmente, ao sindicato, as arrecadações tributárias por imposição do próprio Estado, de modo a legitimar a legislação em nome do sindicato.

Disso advém a assertiva de que o sindicato teria competência para impor contribuições à integralidade das categorias profissionais e econômicas, que se dava a partir da letra e do artigo 513 da CLT. Tem-se, portanto, um sindicato, instrumentalizado por um tributo estatal, subsistindo as expensas do Estado, vigiado por este, situação esta que, inequivocamente, traz a tona o fato de que perdeu a sua autonomia. Se todas as categorias de controle que o sistema sindical pátrio determina ao sindicato cessassem, por uma reforma integral da lei sindical, satisfaria a manutenção do referido tributo para inteirar-Ihe qualquer inconstância de liberdade (GOMES, 1984, p. 714-715).

Todavia, essa não é a essência da contribuição sindical obrigatória, pois esta não fora criada para que o sindicato subsistisse à custa do Estado, mas que por meio deste fossem aplicadas finalidades assistenciais, proibindo, assim, que fossem aplicadas na manutenção dos seus serviços normais, que em tese deveriam ser atendidos pelas suas rendas próprias (VIANNA, 1972, p. 112).

As entidades sindicais têm o dever de se consolidar mediante estatutos assentidos em assembleia nos moldes previstos pela legislação. Tais regulamentos, 


\section{Personalidade Acadêmica Homenageada:}

Carlos Aurélio Mota de Souza (Universidade Ibirapuera - UNIB)

além de proveitos, determinam deveres aos filiados, dentre as quais se encontra a incumbência de contribuir financeiramente em prol da entidade sindical (OLIVEIRA NETO, 2010, p. 74).

Afiliar-se ao ente sindical deve ser um ato facultativo, todavia, poderia ser formada uma cota, a fim de amparar os dispêndios de representação, principalmente no que se relaciona às negociações coletivas, até mesmo porque, não aparenta ser justo que os trabalhadores não afiliados aos sindicatos não contribuam com as expensas das negociações que tiram benefício direto.

\subsection{O FIM DA CONTRIBUIÇÃO SINDICAL COMPULSÓRIA}

A denominada Reforma Trabalhista a partir da Lei 13.467 de 2018, mediante a modificação da Consolidação das Leis Trabalhistas trouxe a revogação da contribuição sindical obrigatória, base de sustentação financeira do sistema sindical, patronal e profissional, evidenciando que os empregadores somente poderão ser exigidos o desconto em folha dos seus funcionários, somente se por eles houver autorização expressa. Os artigos 578, 579 e 582 da CLT expressaram a partir de 11 de novembro de 2017, data da vigência da lei, a natureza facultativa das contribuições sindicais profissionais e patronais.

Consequentemente, debilita-se a importância do controle administrativo da unicidade sindical pelo Ministério do Trabalho. Melhor dizendo, o exercício do direito à liberdade sindical na criação de associação profissional ou sindical passa a alcançar força natural e a entidade estaria reconhecida pelo número de associados, e não mais por consequência de ato administrativo do poder executivo.

Imprescindível ressaltar, suficientemente acerca do histórico do movimento sindical brasileiro, para admitir que o texto de 1988 ocasionou inovações ao sistema sindical brasileiro, atenuando, de alguma forma, o modelo corporativo demasiadamente regulado pelo governo desde a era Vargas.

Dentre as medidas empregadas, salienta-se: o direito à livre constituição de sindicatos, desobrigado a aquiescência do Ministério do Trabalho; a recognição constitucional da consolidação sindical na representação da categoria; a liberdade 


\section{Personalidade Acadêmica Homenageada:}

Carlos Aurélio Mota de Souza (Universidade Ibirapuera - UNIB)

de afiliação e consequente te desfiliação dos sindicatos; a compulsoriedade da cooperação sindical nas negociações coletivas; a probabilidade de instauração, mediante assembleia, de contribuição confederativa (PEREIRA NETO, 2017, p. 36).

Importante ressaltar, que a Constituição Federal de 1988 é considerada como predecessora de diversos tempos no que diz respeito ao direito sindical, especialmente em virtude dos princípios previstos no art. 8ํㅡ, I, quais sejam, a não intervenção e a não interferência do Estado na organização sindical que possibilitou a majoração do número de entidades sindicais, incentivou a cessação da Comissão de Enquadramento Sindical e propiciou a criação do Cadastro Nacional das Organizações Sindicais do Brasil.

Portanto, mesmo que a unicidade sindical e, de modo consequente, a representação sindical forçosa por categoria não sejam consideradas as melhores particularidades de um sistema sindical, necessário reconhecer sua função histórica relevante, principalmente na década de 1940 do século XX, quando a classe trabalhadora, ainda difusa em um território continental, sem qualquer densidade ou coesão para negociar com a classe patronal, tinha a voz de uma organização, cujas atribuições foram úteis para demarcar a posição e defesa dos interesses de seus substituídos (SAAD, 2017, p. 53).

Não se pode deixar de visualizar que uma das repercussões primordiais da obrigatoriedade da representação descansa no resultado erga omnes das normas que se originam de negociações coletivas, de acordo com o previsto no artigo 611 da Consolidação das Leis Trabalhistas. A auto prestabilidade das normas coletivas para toda a categoria profissional, bem como a recognição constitucional dos acordos e convenções coletivas também tonificam a relevância da missão das organizações sindicais na negociação coletiva (PEREIRA NETO, 2017, p. 60-61).

Nesse sentido, o debate acerca da constitucionalidade, ou não, da desconstituição da obrigatoriedade da contribuição sindical há que ser acomodada a essa sistemática sindical integral, sob pena de mutação do regime sindical concebido em 1988 e da insatisfação de toda uma série de direitos fundamentais sociais, os quais direta ou indiretamente, nele estão firmados. 


\section{Personalidade Acadêmica Homenageada:}

Carlos Aurélio Mota de Souza (Universidade Ibirapuera - UNIB)

\section{CONCLUSÃO}

Através de leis e decretos foram delimitadas a estrutura dos sindicatos, no que concerne a sua estrutura de ação, especificando suas atribuições, estipulando desde o conteúdo e os possíveis efeitos da convenção coletiva, até os impactos de uma eventual paralisação, ou mesmo impedindo abusos contra manifestações sindicais, resguardando o operário e seu representante sindical, idealizando a formação de mecanismos para a preservação da paz social, determinando as generalidades de algumas temáticas a serem debatidas em negociação coletiva, como meio de proteção aos direitos do trabalhador.

Portanto, muito embora seja previsão constante da Carta Magna, a liberdade sindical é muito reduzida, não tendo sido realizada até os dias atuais, qualquer reestruturação significativa do padrão sindical de Getúlio Vargas. Desta maneira, pode-se dizer que há no Brasil, um modelo antiquado, ainda não ajustado a algumas das resoluções da OIT, como a viabilidade de o trabalhador adotar o sindicato que Ihe represente, rechaçando-se assim a imposição de um sindicato por base territorial para cada classe profissional.

Além do mais, ao modelo de unicidade sindical, as entidades sindicais no Brasil acabaram por ficar adstritas ao Estado, em virtude de, antes da Reforma Trabalhista serem mantidas mediante uma contribuição de caráter compulsório criada pelo Estado, compelindo o trabalhador a cumprir essa contribuição diretamente ao sindicato. De mais a mais, a despeito de terem conquistado uma certa autonomia para o exercício de suas funções, o Ministério Público, assim como na Era Vargas, ainda exerce determinado poder de intervenção em negociações coletivas, tendo, inclusive, permissivo legal para ser parte em ações coletivas de dissídio coletivo, com o propósito de resolução de greve, meio este empregado pelos sindicatos como forma de pressionar para conquistarem melhores direitos na negociação coletiva.

Comparativamente, as organizações sindicais cessaram a intervenção estatal, em sua organização sindical, e suportaram a criação do seu estatuto no qual 


\section{Personalidade Acadêmica Homenageada:}

Carlos Aurélio Mota de Souza (Universidade Ibirapuera - UNIB)

fora garantido o profuso exercício de greve, com algumas ressalvas no sentido de que na busca da melhoria das condições dos direitos dos trabalhadores, não fossem lesados os interesses da sociedade, todavia, tais mudanças se deram logo após a queda de Getúlio Vargas, sem qualquer mudança significativa até hoje.

A imperatividade da contribuição a um determinado sindicato, precedentemente definido mediante a unicidade, indica grave afronta ao instituto da liberdade sindical. A contribuição sindical forçada e destinada a todos os intervenientes da categoria, seja econômica ou profissional, submete a todos, independentemente de afiliação. A contribuição obrigatória pode ser encarada como um dos grandes inconvenientes à concretização da liberdade sindical em nosso país, uma vez que não proporciona ao contribuinte o poder de eleger para qual associação sindical participar.

A afiliação mandatória ao sindicato atenta em face da liberdade sindical negativa, de outra maneira, o direito dos trabalhadores da classe patronal de não se afiliarem a qualquer entidade sindical. Caso a liberdade sindical se desse em sua plenitude no ordenamento jurídico brasileiro, os sindicatos teriam que se mostrar representativos para conseguirem mais associados.

No que diz respeito às contribuições confederativa e assistencial, resta, pois, evidente, que somente são cabíveis se impostas aos associados do sindicato, uma vez que é nula a instituição mediante norma coletiva a qualquer título, obrigando trabalhadores não sindicalizados, independentemente da existência ou não de oposição ao desconto, visto que tal prática ofende o direito de livre associação e sindicalização.

As contribuições em favor das entidades sindicais impostas somente aos membros sindicalizados seria um modelo ideal de sindicalismo. Assim a contribuição estimularia boas práticas que remeteriam à captação de associados. A parcela sindical ofertada aos associados e a contribuição de solidariedade designada aos não associados que forem favorecidos pelas negociações coletivas comparecem como as únicas modalidades de custeamento sindical em total conformidade com os preceitos da liberdade sindical. 
Personalidade Acadêmica Homenageada:

Carlos Aurélio Mota de Souza (Universidade Ibirapuera - UNIB)

Destarte, os sindicatos que de fato têm possibilidade e competência em reunir filiados e fazer convenções com um extenso número de associados, da mesma maneira que representar com dignidade as suas classes pertencentes, subsistirão, eis que o trabalhador tem interesse na conservação de sua estrutura. Já aqueles que não representam acertadamente seus empregados, cederão.

Portanto, é evidente a imprescindibilidade de que o sindicalismo se obrigue a evoluir no intuito de efetivamente, assegurar representatividade e legitimidade aos seus representados, em que se almeja que o sindicalismo se desenvolva de forma a conquistar novos métodos de despertar o interesse da coletividade, a afeição dos trabalhadores para então poder verdadeiramente tutelar o direito dos trabalhadores.

\section{REFERÊNCIAS}

AROUCA, José Carlos. O sindicato em um Mundo Globalizado. São Paulo, Ed. LTr, 2003.

BATALHA, Wilson de Souza Campos. Sindicatos, sindicalismo. São Paulo, Ed LTr, 1992.

GERNIGON, Bernard. Liberdade Sindical. In: Fórum Internacional sobre Direitos Humanos e Direitos Sociais. São Paulo: LTr, 2004.

GUNTHER, Luiz Eduardo. O fim da contribuição sindical obrigatória: a crônica de uma morte anunciada. In Reforma Trabalhista Ponto a Ponto. São Paulo: Editora LTr, p. 2018.

LOBATO, Marthius Sávio Cavalcante. O valor constitucional para efetividade dos direitos sociais nas relações de trabalho. São Paulo: LTr, 2006.

MARTINS, Sergio Pinto. Direito do trabalho. 26 ed. São Paulo: Atlas, 2010.

NASCIMENTO, Amauri Mascaro; NASCIMENTO, Sônia Mascaro; NASCIMENTO, Marcelo Mascaro. Direito sindical. 8ª ed. São Paulo: LTR, 2015.

NETO, Francisco Ferreira Jorge; CAVALCANTE, Jouberto de Quadros Pessoa; Manual do Direito do Trabalho, Tomo II, Ed. Lumen Juris, 2004.

OLIVEIRA NETO, Alberto Emiliano de Oliveira. Contribuições sindicais. 1. ed, São Paulo: LTr, 2010. 
PEGO, Rafael Foresti. Fundamentos do Direito Coletivo do Trabalho. 1. Ed, Porto Alegre: Livraria do Advogado, 2012.

PEREIRA NETO, João Batista. O sistema brasileiro de unicidade sindical e compulsoriedade de representação. São Paulo : LTR, 2017.

SAAD, Eduardo Gabriel. Federação, confederação e central sindical, apud PEREIRA NETO, João Batista. 0 sistema brasileiro de unicidade sindical e compulsoriedade de representação. São Paulo : LTR, 2017.

SUSSEKIND, Arnaldo, Instituições de Direito do Trabalho. Vol. 2, $19^{\mathrm{a}}$ ed. São Paulo: LTr, 2000.

VIANAS, Segadas. "Instituições de direito do trabalho" em co-autoria com Arnaldo Sussekind e Delio Maranhão, 8 Ed. Rio de Janeiro, Freitas Bastos, 1981.

VIANNA, Márcio Túlio (coord); PORTO, Lorena Vasconcelos; OLIVEIRA, Florença Dumont (Colab). Reforma Sindical, no âmbito da nova competência trabalhista. Belo Horizonte: Mandamentos, 2005.

VIANNA, Segadas. Direito Coletivo do Trabalho. São Paulo: LTr, 1972. 